\title{
Comparative mRNA Expression of eEF1A Isoforms and a PI3K/Akt/mTOR Pathway in a Cellular Model of Parkinson's Disease
}

\author{
Kawinthra Khwanraj, Suriyat Madlah, \\ Khwanthana Grataitong, and Permphan Dharmasaroja \\ Department of Anatomy, Faculty of Science, Mahidol University, Bangkok 10400, Thailand \\ Correspondence should be addressed to Permphan Dharmasaroja; permphan.dha@mahidol.ac.th
}

Received 14 October 2015; Revised 23 December 2015; Accepted 19 January 2016

Academic Editor: Hélio Teive

Copyright (C) 2016 Kawinthra Khwanraj et al. This is an open access article distributed under the Creative Commons Attribution License, which permits unrestricted use, distribution, and reproduction in any medium, provided the original work is properly cited.

The PI3K/Akt/mTOR pathway is one of dysregulated pathways in Parkinson's disease (PD). Previous studies in nonneuronal cells showed that Akt regulation can be increased by eukaryotic protein elongation factor 1 alpha 2 (eEF1A2). eEF1A2 is proposed to contribute protection against apoptotic death, likely through activation of the PI3K/Akt pathway. Whether eEF1A2 plays a role in the prevention of cell death in PD has not been investigated. Recently, gene profiling on dopaminergic neurons from postmortem PD patients showed both upregulation and downregulation of some PI3K and mTOR genes. In this paper, the expression of all gene members of the PI3K/Akt/mTOR pathway in relation to those of the eEF1A isoforms in a cellular model of PD was investigated at the mRNA level. The results showed a similar trend of upregulation of genes of the eEF1A isoforms (eEF1A1 and eEF1A2) and of the PI3K (classes I-III)/Akt (Akt1, Akt2, and Akt3)/mTOR ( $m$ TORC1 and $m$ TORC2) pathway in both nondifferentiated and differentiated SH-SY5Y dopaminergic cells treated with 1-methyl-4-phenylpyridinium $\left(\mathrm{MPP}^{+}\right)$. Upregulation of eEF1A2, Akt1, and mTORC1 was consistent with the relative increase of eEF1A2, Akt, phospho-Akt, and mTORC1 proteins. The possible role of eEF1A isoforms in the regulation of the PI3K/Akt/mTOR pathway in PD is discussed.

\section{Introduction}

The phosphatidylinositol 3-kinase (PI3K)/Akt serine/threonine protein kinase $(\mathrm{Akt}) /$ mammalian target of rapamycin kinase (mTOR) pathway is a crucial signaling mediator, which seems to serve as a connection between aspects of neuronal proliferation, differentiation, and programmed apoptotic death $[1,2]$. The PI3K/Akt/mTOR system is also viewed as one amongst the key neuroprotective signaling pathways [3]. Activation of the PI3K/Akt pathway, as a neuroprotective effect of caffeine, has been shown in a cellular model of Parkinson's disease (PD) [4]. Treatment with 1methyl-4-phenylpyridinium $\left(\mathrm{MPP}^{+}\right)$leads to increased dephosphorylation of mTOR and its substrate, p70S6K, in both control and G2019S LRRK2-mutant skin fibroblasts [5]. Several studies also support possible pharmacological prevention of dopaminergic neuron death through Akt and mTOR [6-9]. Inhibition of mTOR using rapamycin has been reported to suppress PINK1 and Parkin pathology [10]. After activation, mTOR further activates its downstream effectors that regulate the transcription of many genes and the synthesis of proteins [11].

eEF1A (eukaryotic protein elongation factor 1 alpha) proteins are GTP-binding proteins that bind to aminoacylated tRNA and deliver them to the ribosome during the elongation process of protein translation. There are two isoforms of eEF1A: eEF1A1 and eEF1A2, which share $>90 \%$ sequence identity [12]. eEF1A1 is widely expressed, whereas eEF1A2 is specifically expressed in the brain, heart, and skeletal muscles [12-14]. In addition to their canonical function in translation elongation, binding of eEF1A1 to actin filaments and microtubules suggests its role in actin binding/bundling and microtubule bundling/severing [15]. eEF1A2 has been reported to interact with M4 muscarinic acetylcholine receptors (mAChR) in the brain [16]. eEF1A2 is considered an important human oncogene. Its increased 
expression has been found in tumors of the ovary, breast, and lung [17-20]. The molecular mechanisms underlying progressive dopaminergic cell death in the nigrostriatal pathway of PD patients are not completely understood. Recent genetic and functional analyses show that there are pathogenic overlaps between cancer and PD [21]. In the BT549 human breast cancer cell line, eEF1A2 regulates cancer formation through Akt and PI3K-dependent remodeling of the cytoskeleton [22]. In mouse plasmacytomas, Eefla2 regulates tumor growth and proliferation through activation of the JAK/STAT and Akt signaling pathways [23].

Overexpression of eEF1A2 also protects cells against apoptotic death induced by oxidative stress [24]. eEF1A2 is found to interact with peroxiredoxin-I (Prdx-I), a typical 2Cys peroxiredoxin, widely expressed in all mammalian cells [25]. Prdx-I functionally protects cells from oxidative stressinduced cell damage by reducing a range of reactive oxygen species (ROS) production. The interaction of eEF1A2 with Prdx-I provides an increase in protection from oxidative stress-induced death. This protection is correlated with the decrease in cleavage of caspases 3 and 8 and elevated expression of prosurvival Akt.

Whether eEF1A1 or eEF1A2 plays a role in the prevention of cell death in PD has not been investigated. The aim of our study was to analyze the pattern of gene expression for eEF1A isoforms in relation to that of the PI3K/Akt/mTOR pathway. Thus, we evaluated real-time mRNA expression of PI3K isoforms: PI3K classes I, II, and III; Akt isoforms: Akt1 and Akt2; and mTOR isoforms: mTORC1 and mTORC2, together with the expression of eEF1A1 and eEF1A2 mRNAs, using an $\mathrm{MPP}^{+}$-induced SH-SY5Y cellular model of PD. We expected that there would be a similar trend of increased expression of eEF1A isoforms and of the PI3K/Akt/mTOR pathway. Indirectly we expected the result to suggest whether any eEF1A isoforms could become a novel prosurvival factor in protecting dopaminergic cells against toxin-induced neuronal death.

\section{Materials and Methods}

2.1. Materials. Eagle's Minimum Essential Medium (MEM), Nutrient Mixture Ham's F12 medium (F12), fetal bovine serum (FBS), and other supplements for cell culture were purchased from Gibco (Gaithersburg, MD, USA). Retinoic acid (RA), 1-methyl-4-phenylpyridinium $\left(\mathrm{MPP}^{+}\right)$, 3-(4,5dimethylthiazol-2-yl)-2,5-diphenyltetrazolium bromide (MTT), and DMSO were purchased from Sigma-Aldrich (St. Louis, MO, USA). Primers for real-time RT-PCR were synthesized by and purchased from Biolegio (Nijmegen, Netherlands). Antibodies against Akt, phosphorylated Akt, phosphorylated mTORC1, and tyrosine hydroxylase (TH) were purchased from Cell Signaling Technology (Danvers, MA, USA). Antibody against eEF1A2 and anti- $\beta$-actin were purchased from Sigma-Aldrich (St. Louis, MO, USA). Horseradish peroxidase- (HRP-) conjugated anti-rabbit IgG and HRP-conjugated anti-mouse IgG were purchased from Abcam (Cambridge, UK) and Invitrogen (Eugene, OR, USA), respectively.
2.2. Culture and Treatment of SH-SY5Y Cells. SH-SY5Y human neuroblastoma cells were grown in $1: 1$ mixture of MEM and F12, supplemented with 10\% heat-activated FBS. Cells were separated into two groups: nondifferentiated and differentiated cells. For neuronal differentiation of SH-SY5Y cells, RA was added a day after plating at final concentration $10 \mu \mathrm{M}$ in MEM-F12 with $10 \%$ FBS and maintained for three days. Neuronal differentiation was demonstrated as an increase in tyrosine hydroxylase $(\mathrm{TH})$ expression using immunostaining. Thereafter, nondifferentiated and differentiated SH-SY5Y cells were exposed to $125,250,500,1000$, and $2000 \mu \mathrm{M}$ of $\mathrm{MPP}^{+}$for 24 hours. The control groups for nondifferentiated and differentiated SH-SY5Y cells were treated with the same medium without $\mathrm{MPP}^{+}$.

2.3. Immunostaining for Tyrosine Hydroxylase. SH-SY5Y cells were fixed in $4 \%$ paraformaldehyde for 15 minutes at room temperature followed by sequential incubation with permeabilizing solution ( $0.2 \%$ Triton X-100) in PBS for 30 minutes at room temperature. Then, cultures were washed again with PBS and incubated in blocking solution (3\% BSA in $0.5 \%$ Tween 20 in PBS) for 30 minutes. Cells were incubated with rabbit polyclonal antibody against TH (1:200 dilution in blocking solution; Merck Millipore AB152) overnight at $4^{\circ} \mathrm{C}$. After washing, cells were incubated with 1:500 dilution of Alexa 488-conjugate secondary antibody for 1 hour at room temperature. Coverslips were then mounted with Vectashield antifading mounting medium with DAPI (Vector laboratories, CA). Cells were visualized under a confocal laser-scanning microscope (Olympus model FV 1000; Tokyo, Japan).

2.4. Cell Viability Assay. SH-SY5Y cells were seeded onto a 96-well plate at a density of $1 \times 10^{4}$ cells/well in $200 \mu \mathrm{L}$ of medium and incubated at $37^{\circ} \mathrm{C}$ under $5 \% \mathrm{CO}_{2}$. After exposure to $\mathrm{MPP}^{+}$, cell viability was measured by MTT colorimetric assay. This method was based on the reduction of tetra ring of MTT by mitochondrial dehydrogenases with $\mathrm{NADH}$ in the active mitochondria, yielding a blue formazan product, which can be measured spectrophotometrically. After incubation, $20 \mu \mathrm{L}$ of MTT $(5 \mathrm{mg} / \mathrm{mL})$ was added to each well and the cells were cultured for another $4 \mathrm{~h}$; then medium was removed and $100 \mu \mathrm{L}$ of DMSO was added to each well to dissolve the formazan. The color reaction was measured at wavelength $570 \mathrm{~nm}$ with a reference at $690 \mathrm{~nm}$ using the VERSAmax Tunable microplate reader with SoftMax Pro software (Molecular Devices, Sunnyvale, CA, USA).

2.5. Real-Time Quantitative PCR Analysis. SH-SY5Y cells were seeded onto 6-well plates. Total mRNA was extracted from the pellet using PARIS kit according to the supplier's instructions. DNase I treatment was performed after RNA extraction, followed by heat inactivation. The quantity and purity of RNA were determined by optical density measurements at OD A260/A280 ratio with 1.8 or above using Nanodrop 2000 spectrophotometer (Thermo Fisher Scientific Inc., Wilmington, DE, USA). Later, the cDNA was synthesized from $1 \mu \mathrm{g}$ of RNA using Masterscript RT-PCR 
System (5 PRIME, Gaithersburg, MD, USA), according to the manufacturer's instructions, and stored at $-20^{\circ} \mathrm{C}$ until assay. KAPA SYBR FAST qPCR kit (Kapa Biosystems, Woburn, MA, USA) was used for real-time PCR quantification. The $20 \mu \mathrm{L}$ real-time PCR reaction mixture contained $20 \mathrm{ng}$ cDNA template, $10 \mu \mathrm{L}$ of $1 \mathrm{x}$ KAPA SYBR FAST qPCR master mix, $200 \mathrm{nM}$ of forward and reverse primers, and PCR-grade water. $\beta$-Actin was used as a reference gene. The sequences of the primers are shown in Table 1 [26-28]. The reaction was performed in the Applied Biosystems 7500 real-time PCR system (Applied Biosystems, Foster City, CA, USA) with the PCR cycling conditions as follows: 3 minutes for enzyme activation at $95^{\circ} \mathrm{C}, 40$ cycles of 3 seconds for initial denaturation at $95^{\circ} \mathrm{C}$, and annealing/extension at $60^{\circ} \mathrm{C}$ for 1 minute. Melting curve analysis was performed to verify specificity of each primer after PCR to ensure amplification specificity. The threshold cycle (Ct) number was determined and used in the comparative $\mathrm{Ct}$ method. The relative quantity of the target gene was estimated by the $2^{-\Delta \Delta \mathrm{Ct}}$ method. All data was analyzed by the ABI 7500 software, version 2.0.

2.6. Western Blot Analysis. SH-SY5Y cells were seeded at an initial concentration of $2 \times 10^{5}$ cells/well in 6-well plates. After treatment with $\mathrm{MPP}^{+}$for 24 hours, cells were trypsinized and centrifuged to collect the pellet. Cold RIPA buffer $(50 \mathrm{mM}$ Tris $\mathrm{PH} 7.4,150 \mathrm{mM} \mathrm{NaCl}, 1 \%$ triton X-100, $0.1 \%$ SDS, $1 \%$ sodium deoxycholate, $5 \mathrm{mM}$ EDTA, $30 \mathrm{mM} \mathrm{Na} \mathrm{HPO}_{4}$, and $50 \mathrm{mM} \mathrm{NaF}$ ) was added to the pellets, mixed, and incubated on ice for 20 minutes, followed by centrifugation. The supernatants were collected and kept at $-80^{\circ} \mathrm{C}$ until being used. Sixty $\mu$ g of protein extracts was separated in $8 \%$ sodium dodecyl sulfate-polyacrylamide gel electrophoresis (SDS-PAGE) and then transferred onto a nitrocellulose membrane. The membrane was blocked with $5 \%$ nonfat dry milk in $1 \mathrm{x}$ Tris-buffered saline containing $0.1 \%$ Tween 20 for 2 hours. It was then incubated with rabbit polyclonal anti-EEF1A2 (1:2000 dilution), rabbit monoclonal anti-Akt (1:1000 dilution), rabbit monoclonal anti-phosphorylated Akt at serine 473 (1:1000 dilution), rabbit monoclonal antiphosphorylated mTORC1 at Ser 2448 (1:1000 dilution), or mouse monoclonal anti- $\beta$-actin (1:5000 dilution) overnight at $4^{\circ} \mathrm{C}$. Subsequently the membrane was incubated with HRPconjugated secondary antibodies (1:2000-5000 dilution) for 2 hours at $4^{\circ} \mathrm{C}$. The bands were visualized using ECL Prime Western Blotting Detection (GE Healthcare, Buckinghamshire, UK). The signal intensities were determined by densitometry using Image-J software (National Institutes of Health, Bethesda, Maryland, USA).

2.7. Statistical Analysis. Experiments on cell viability assay and real-time quantitative PCR were repeated three times in triplicate measurement. Statistical analyses were performed with one-way ANOVA test followed by a post hoc analysis (Tukey's multiple comparison test) using GraphPad Prism 5 Software for Windows (GraphPad Software, Inc., San Diego, CA, USA). All values were expressed as mean \pm standard error of the mean (mean \pm SEM) for each group. A $P$ less than 0.05 was considered statistically significant.
TABLE 1: List of primer pairs used for real-time quantitative PCR.

\begin{tabular}{|c|c|}
\hline Gene symbol & Primers sequences $5^{\prime}-3^{\prime}$ \\
\hline \multirow{2}{*}{ eEF1A1 } & GGCATACCCGAGAGCATG \\
\hline & AGGCATGTTAGCACTTGGC \\
\hline \multirow{2}{*}{ eEF1A2 } & GAGCССТСССССАAСАTGCC \\
\hline & ATGTTCACTGGCGCAAAGGTCAC \\
\hline \multirow{2}{*}{ PIK3CA } & TGGATGCTCTACAGGGCTTT \\
\hline & GTCTGGGTTCTCCCAATTCA \\
\hline \multirow{2}{*}{ PIK3CB } & GCATTAAAAGGGAGCGAGTG \\
\hline & CATGCCGTCGTAAAATCAGA \\
\hline \multirow{2}{*}{ PIK3CD } & CTGGCTGAAGTCCAAGAACC \\
\hline & CTCGGATCATGATGTTGTCG \\
\hline \multirow{2}{*}{ PIK3CG } & ATACCATGATAGCGCCCTTG \\
\hline & AATCACAGCGAACCTCTGCT \\
\hline \multirow{2}{*}{ PIK3C2A } & GAAAAACGAGGAATCCGACA \\
\hline & CAGGGTTACTCCACCCAAGA \\
\hline \multirow{2}{*}{ PIK3C2B } & TTCCCTAGTCGCTTCGTGAT \\
\hline & CAGTGGGTGGAAGAAGGTGT \\
\hline \multirow{2}{*}{ PIK3C2G } & TTCATCTCCCAGATGGCTCT \\
\hline & AGTGGGGTCCGTACATTTTG \\
\hline \multirow{2}{*}{ PIK3C3 } & TCAGCCAAGCATTGTTGAAG \\
\hline & TCCACTTTCGCGTTGTACTG \\
\hline \multirow{2}{*}{$A k t 1$} & TCTATGGCGCTGAGATTGTG \\
\hline & CTTAATGTGCCCGTCCTTGT \\
\hline \multirow{2}{*}{$A k t 2$} & TATACCGCGACATCAAGCTG \\
\hline & GGTCCCACAGAAGGTTTTCA \\
\hline \multirow{2}{*}{ Akt3 } & TGGACAAAGATGGCCACATA \\
\hline & ACTGCTCGGCCATAGTCATT \\
\hline \multirow{2}{*}{ mTORC1 } & AGGCCGCATTGTCTCTATCAA \\
\hline & GCAGTAAATGCAGGTAGTCATCCA \\
\hline \multirow{2}{*}{ mTORC2 } & TCTACCACGACAGCCCGGCA \\
\hline & TGGGGGCCCCGTTCCATCAT \\
\hline \multirow{2}{*}{$\beta$-Actin } & CATGTACGTTGCTATCCAGGC \\
\hline & CTCCTTAATGTCACGCACGAT \\
\hline
\end{tabular}

\section{Results}

3.1. Effect of $\mathrm{MPP}^{+}$on SH-SY5Y Cell Viability. To investigate the influence of $\mathrm{MPP}^{+}$on cell viability in nondifferentiated and differentiated SH-SY5Y neuroblastoma cells, cells were exposed to $125,250,500,1000$, and $2000 \mu \mathrm{M} \mathrm{MPP}^{+}$for 24 hours. For differentiated cells, the cells were incubated with $10 \mu \mathrm{M}$ RA for 3 days to induce neuronal differentiation prior to exposure to various dosages of $\mathrm{MPP}^{+}$. Differentiation of SH-SY5Y cells to a neuronal phenotype was confirmed by an increase in the expression of tyrosine hydroxylase and neuritic outgrowth (Figure 1). Cell viability was examined with an MTT assay. Cell viability was significantly reduced by all dosages of $\mathrm{MPP}^{+}$in both nondifferentiated and differentiated cells (Figure 2). In nondifferentiated cells, exposure to $500 \mu \mathrm{M} \mathrm{MPP}{ }^{+}$led to reduction of viability by approximately $50 \%$. However, $1000 \mu \mathrm{M} \mathrm{MPP}^{+}$was required to reduce the viability of differentiated cells to about $50 \%$. Overall, higher dosages of $\mathrm{MPP}^{+}$were required to induce cell 

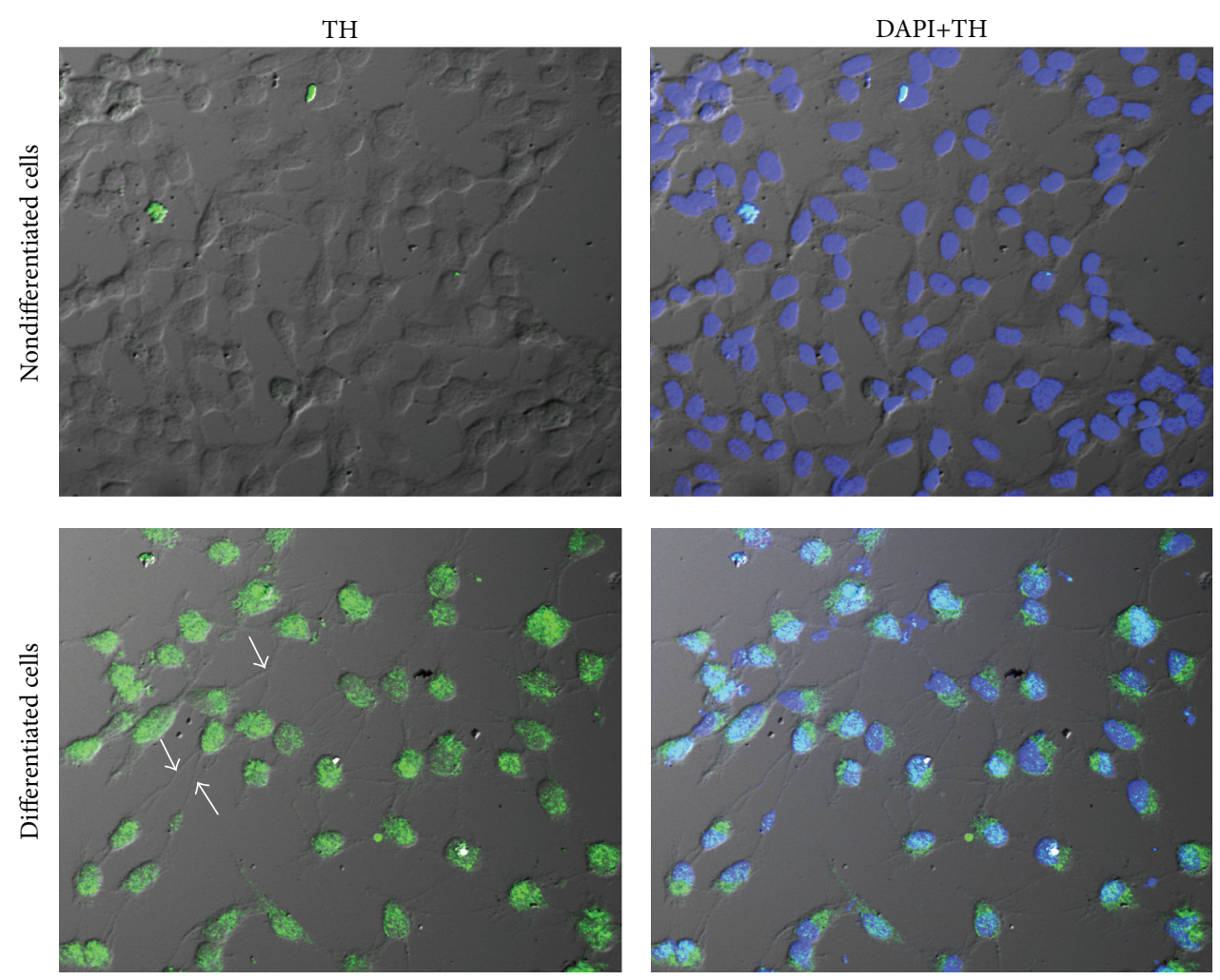

Figure 1: Expression of tyrosine hydroxylase in undifferentiated and differentiated SH-SY5Y cells. Cells were differentiated in $10 \mu \mathrm{M}$ retinoic acid (RA). After differentiation for 3 days, expression of tyrosine hydroxylase (TH) was visualized through immunostaining in undifferentiated cells and RA-differentiated cells. Nuclei were stained using DAPI. White arrows indicate areas of neurite outgrowth.

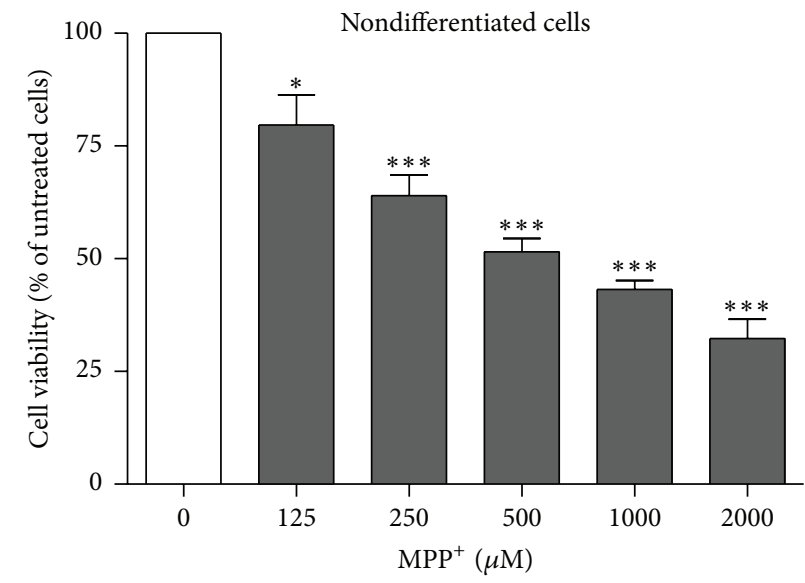

(a)

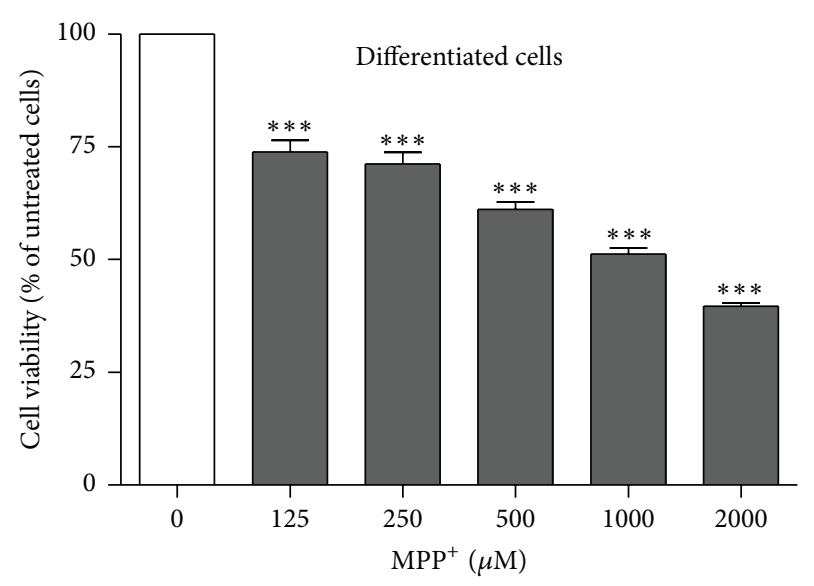

(b)

FIGURE 2: Effect of $\mathrm{MPP}^{+}$on cell viability of nondifferentiated SH-SY5Y cells (a) and effect of $\mathrm{MPP}^{+}$on cell viability of differentiated SH-SY5Y cells (b). Cells were exposed to $125,250,500,1000$, and $2000 \mu \mathrm{M}$ of $\mathrm{MPP}^{+}$for 24 hours and cell viability was measured with an MTT assay. For neuronal differentiation, SH-SY5Y cells were treated with $10 \mu \mathrm{M}$ retinoic acid for three days before exposure to MPP ${ }^{+}$. The control groups for nondifferentiated and differentiated SH-SY5Y cells were treated with the same medium without MPP ${ }^{+}$. MTT assays were repeated three times in triplicate measurement. Data are shown as mean \pm SEM. $*$ indicates $P<0.05$ and $* * *$ indicates $P<0.001$ versus $0 \mu \mathrm{m}$ of MPP ${ }^{+}$. 


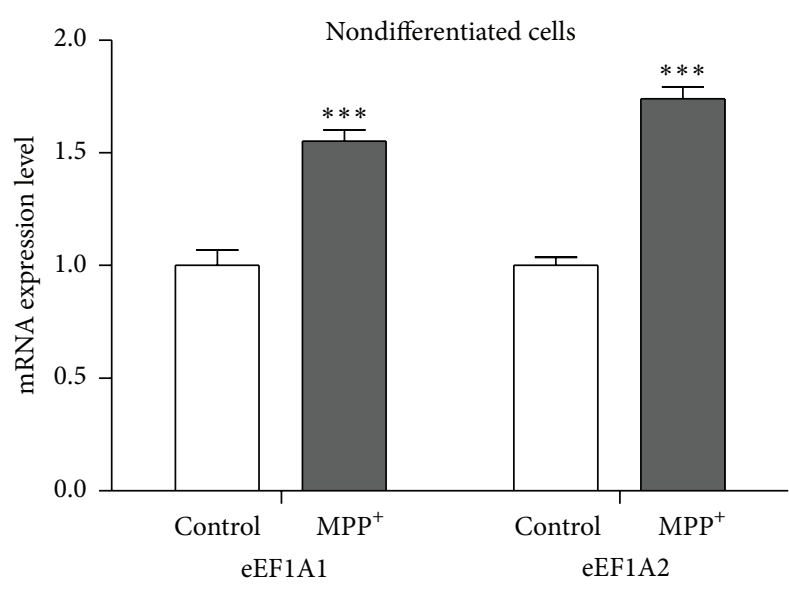

(a)

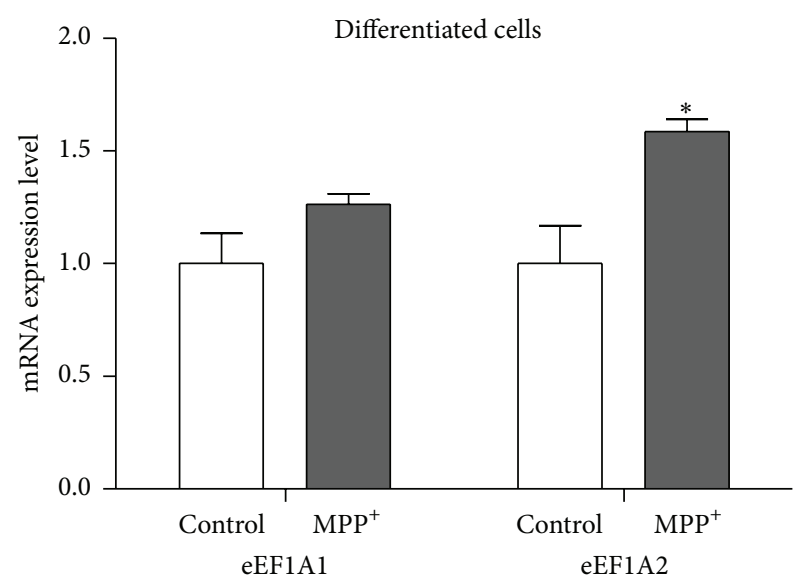

(b)

FIGURE 3: mRNA expression levels of eEF1A1 and eEF1A2 in nondifferentiated SH-SY5Y cells (a) and mRNA expression levels of $e E F 1 A 1$ and eEF1A2 in differentiated SH-SY5Y cells (b). For neuronal differentiation, SH-SY5Y cells were treated with $10 \mu \mathrm{M}$ retinoic acid for three days before exposure to $\mathrm{MPP}^{+}$. The control groups for nondifferentiated and differentiated SH-SY5Y cells were treated with the same medium without $\mathrm{MPP}^{+}$. Real-time quantitative PCRs were repeated three times in triplicate measurement. Data are expressed as relative to a control and shown as mean \pm SEM. $*$ indicates $P<0.05$ and $* * *$ indicates $P<0.001$ versus control of each group.

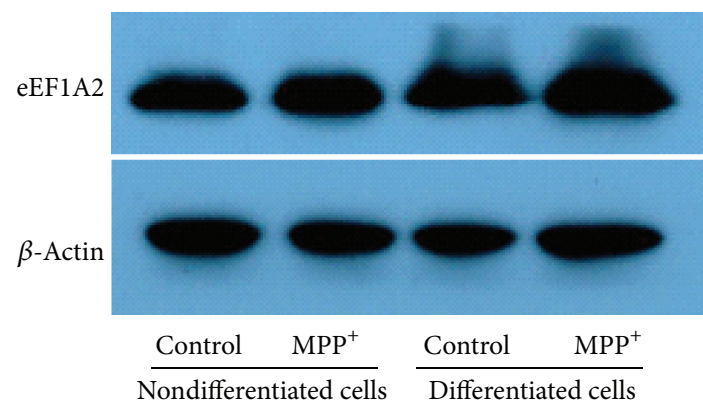

(a)

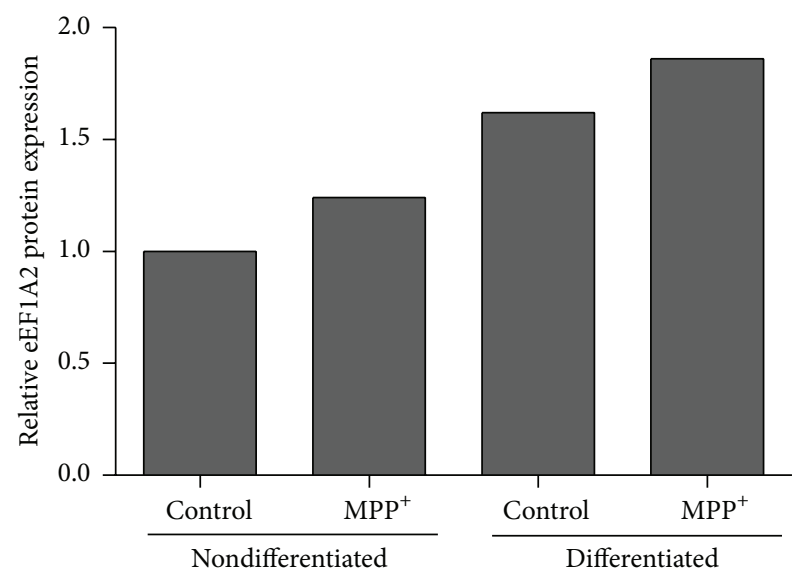

(b)

FIGURE 4: Relative protein expression of eEF1A2 in nondifferentiated and differentiated SH-SY5Y cells by Western blot (a). For neuronal differentiation, SH-SY5Y cells were treated with $10 \mu \mathrm{M}$ retinoic acid for three days before exposure to $\mathrm{MPP}^{+}$. The control groups for nondifferentiated and differentiated SH-SY5Y cells were treated with the same medium without $\mathrm{MPP}^{+}$. (b) represents the quantification of the band density normalized to actin, relative to a nondifferentiated control.

death in differentiated cells compared with nondifferentiated cells. Thus, 500 and $1000 \mu \mathrm{M} \mathrm{MPP}^{+}$were used to treat nondifferentiated and differentiated cells, respectively, in later experiments.

\subsection{Expression of eEF1A1 and eEF1A2. Quantitative real-} time PCR showed that eEF1A1 and eEF1A2 mRNAs were significantly increased in nondifferentiated SH-SY5Y cells after 24-hour exposure to $\mathrm{MPP}^{+}(P<0.001$; Figure 3(a)). In differentiated cells, a significant increase was observed only for eEF1A2 mRNA $(P<0.05$; Figure 3(b)). As the eEF1A2 isoform has been reported to be involved in protection from oxidative stress-induced death, Western blotting was performed subsequently to evaluate eEF1A2 expression at the protein level. The result showed relatively increased levels of the eEF1A2 protein in both nondifferentiated and differentiated cells treated with $\mathrm{MPP}^{+}$(Figure 4), which is consistent with the mRNA result.

3.3. Expression of Akt1, Akt2, and Akt3. After 24-hour exposure to $\mathrm{MPP}^{+}$, a tendency of increased expression of Akt1, Akt2, and Akt3 mRNA was observed in differentiated $\mathrm{SH}$ SY5Y cells, although this could not be confirmed statistically (Figure 5(b)). In nondifferentiated cells, significantly increased expression was observed for Aktl mRNA $(P<$ 0.05 ) and relatively increased expression was observed for Akt3 mRNA (Figure 5(a)). Western blotting using antibodies against Akt did not show significantly increased levels of 


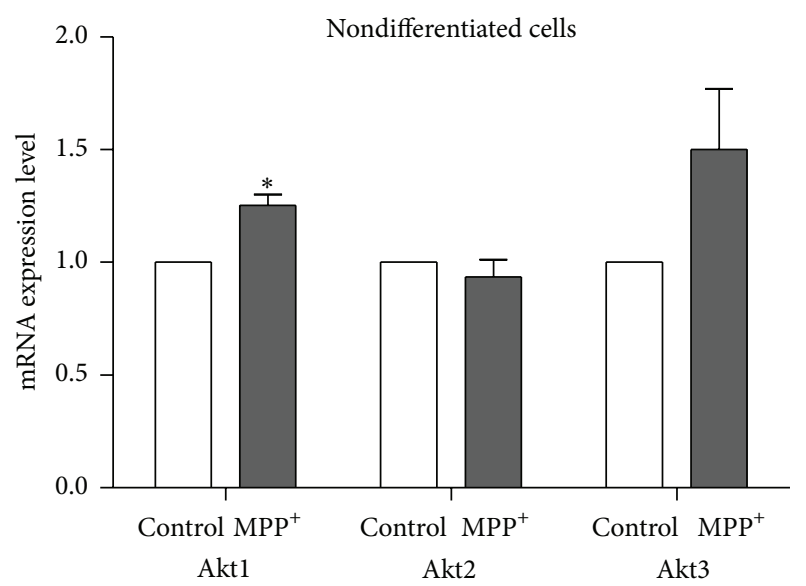

(a)

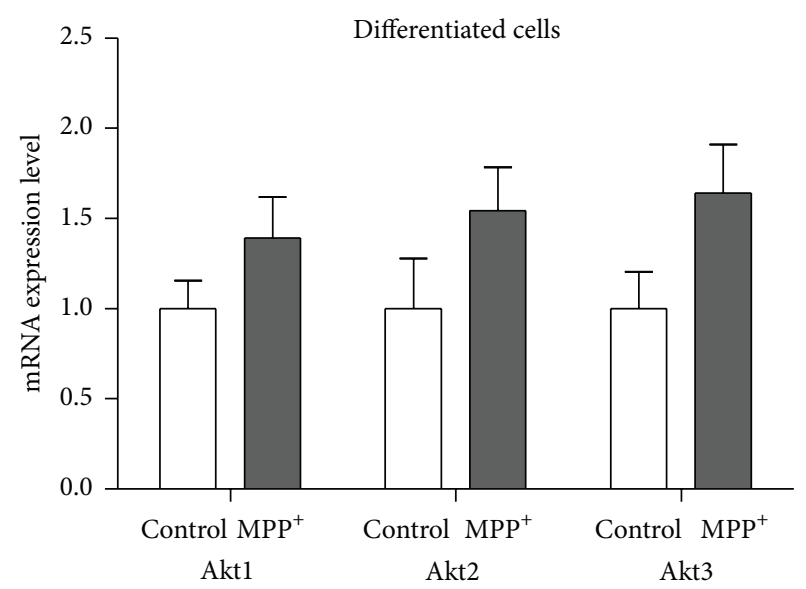

(b)

FIGURE 5: mRNA expression levels of $A k t 1, A k t 2$, and $A k t 3$ in nondifferentiated SH-SY5Y cells (a) and mRNA expression levels of $A k t 1, A k t 2$, and $A k t 3$ in differentiated SH-SY5Y cells (b). For neuronal differentiation, SH-SY5Y cells were treated with $10 \mu \mathrm{M}$ retinoic acid for three days before exposure to $\mathrm{MPP}^{+}$. The control groups for nondifferentiated and differentiated SH-SY5Y cells were treated with the same medium without $\mathrm{MPP}^{+}$. Real-time quantitative PCRs were repeated three times in triplicate measurement. Data are expressed as relative to a control and shown as mean \pm SEM. $*$ indicates $P<0.05$ versus control of each group.

total Akt protein in both nondifferentiated and differentiated cells treated with $\mathrm{MPP}^{+}$(Figure 6). However, when using an antibody against phospho-Aktl (Ser-473), which can also bind to equivalent residues of Akt2 and Akt3, the result showed relatively increased levels of phospho-Akt/total Akt protein in both nondifferentiated and differentiated cells treated with $\mathrm{MPP}^{+}$.

3.4. Expression of $m T O R C 1$ and $m T O R C 2$. Relatively increased mRNA expression levels of MTORC1 and mTORC2 were observed in both nondifferentiated and differentiated SH-SY5Y cells after exposure to $\mathrm{MPP}^{+}$for 24 hours, compared to untreated cells (Figure 7). Significantly increased expression of mTORC1 mRNA was seen in nondifferentiated cells $(P<0.05$; Figure 6(a)). Western blotting using an antibody against Ser-2448 residue of phospho-mTORC1 also showed relatively increased levels of phospho-mTORC1 in both nondifferentiated and differentiated cells (Figure 8), which is consistent with the mTORC1 mRNA result.

3.5. mRNA Expression of PI3Ks. All genes encoding the members of the three human PI3K classes were studied. Class I included PIK3CA, PIK3CB, PIK3CD, and PIK3CG genes. Class II included PIK3C2A, PIK3C2B, and PIK3C2G. Class III included PIK3C3. Quantitative real-time PCR showed that all of the genes encoding class I and II PI3Ks were relatively increased in differentiated SH-SY5Y cells treated with $\mathrm{MPP}^{+}$for 24 hours when compared to untreated cells (Figure 9(b)). Expression of PIK3C was relatively decreased in both differentiated and nondifferentiated cells (Figure 9). Expression of class I and II PI3K genes was somewhat varied in nondifferentiated cells (Figure 9(a)). It should be noted that expression of PIK3C2A was significantly increased in both nondifferentiated and differentiated cells treated with $\mathrm{MPP}^{+}$ $(P<0.05)$.

\section{Discussion}

As expected, we observed similar mRNA expression between both eEF1A isoforms and PI3K/Akt/mTOR in both nondifferentiated and differentiated SH-SY5Y cells. Differentiated and nondifferentiated SH-SY5Y cells have been widely used as a cell model of dopaminergic neurons for PD research. A previous study suggested that differentiated SH-SY5Y cells, induced by low serum and RA treatment, represent a more suitable experimental model for studying the molecular and cellular mechanisms underlying the pathophysiology of PD, as shown by increasing sensitivity to 6-hydroxydopamine (6-OHDA) toxicity during the differentiation process [29]. In contrast, another study suggested that nondifferentiated SH-SY5Y is more appropriate [30]. In the latter study, nondifferentiated SH-SY5Y cells were susceptible to 6-OHDA and $\mathrm{MPP}^{+}$, while RA-differentiated SH-SY5Y cells conferred higher tolerance, potentially by upregulating survival signaling, including the Akt pathway. Thus, we used both nondifferentiated and differentiated SH-SY5Y cells for comparison in the present study.

An interesting finding of this study is the significantly upregulated mRNA expression of eEF1A2 isoform of eEF1A in SH-SY5Y cells after exposure to $\mathrm{MPP}^{+}$. The upregulation was observed in both nondifferentiated and differentiated cells. In contrast, significant upregulation of eEF1A1 was observed in nondifferentiated cells, but not in differentiated cells. The explanation for eEF1A1 upregulation in nondifferentiated cells after $\mathrm{MPP}^{+}$exposure remains to be investigated. Nondifferentiated SH-SY5Y cells contain characteristics of cancer. Upregulation of eEF1A1 may reflect a cellular response to increased synthesis of several intracellular proteins involving pro- and antisurvival processes. The same explanation may be applied to the upregulation of eEF1A2 in nondifferentiated cells. Another hypothesis for eEF1A2 upregulations 


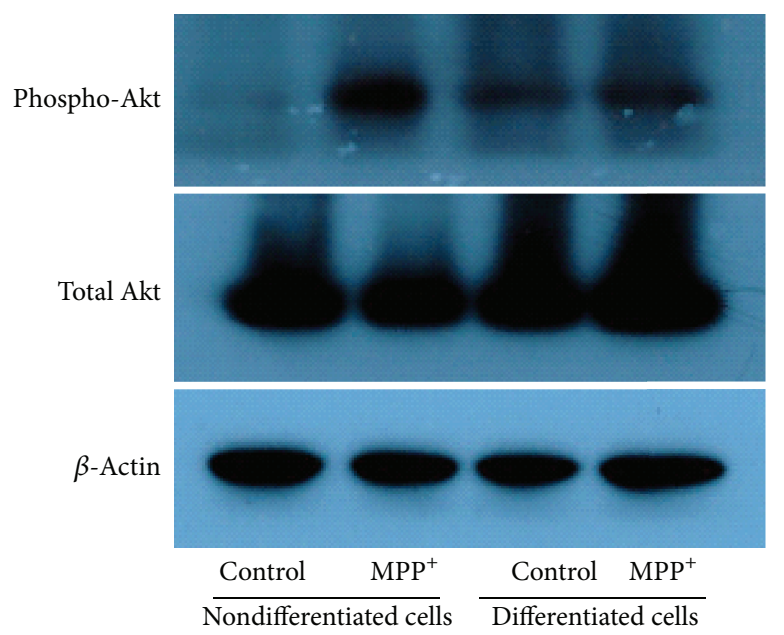

(a)

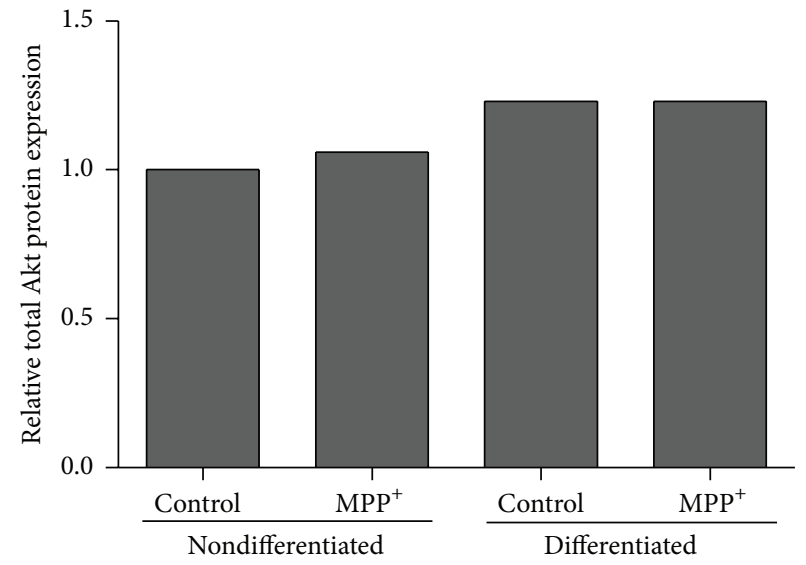

(b)

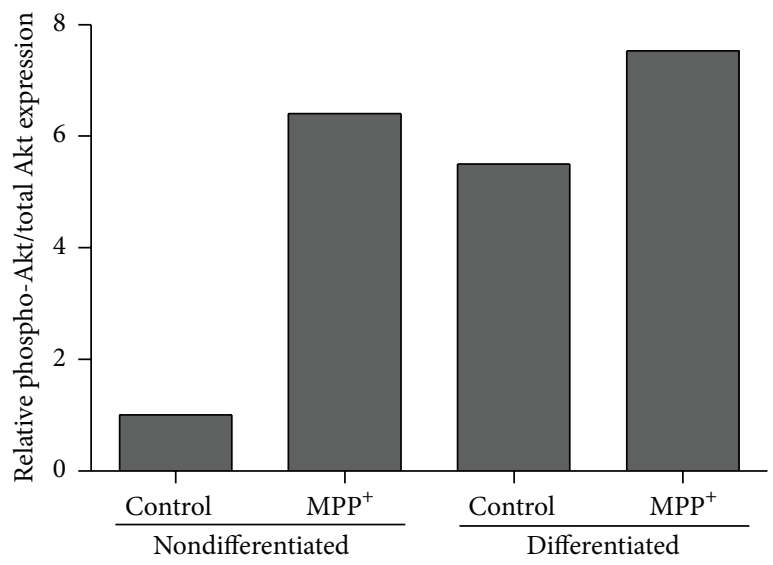

(c)

FIGURE 6: Relative protein expression of total Akt and phospho-Akt in nondifferentiated and differentiated SH-SY5Y cells by Western blot. For neuronal differentiation, SH-SY5Y cells were treated with $10 \mu \mathrm{M}$ retinoic acid for three days before exposure to $\mathrm{MPP}^{+}$. The control groups for nondifferentiated and differentiated SH-SY5Y cells were treated with the same medium without MPP ${ }^{+}$. (b) and (c) represent the quantification of the band density of total Akt and phospho-Akt, respectively. The band density was normalized to actin and relative to a nondifferentiated control.

observed in differentiated cells after $\mathrm{MPP}^{+}$exposure is its role in the protection of cells against oxidative stress. The differentiated SH-SY5Y cells acquire neuronal phenotypes after treatment with RA $[29,30]$. RA treatment confers SHSY5Y cells with higher tolerance to $\mathrm{MPP}^{+}$, potentially by upregulating the survival Akt signaling pathway. Significant upregulation of eEF1A2 but not eEF1A1 in $\mathrm{MPP}^{+}$-treated differentiated SH-SY5Y cells, whose phenotype is dopaminergic, may reflect differential functions of these eEF1A isoforms.

eEF1A2 has been shown to activate prosurvival Akt in a PI3K-dependent manner in a breast cancer cell line [22]. eEF1A2 has also been shown to involve a reduction of apoptosis in mouse plasmacytoma cell lines via activation of Akt [23]. The role of eEF1A2 in resistance to apoptosis has been supported in other cell types [25, 31]. Recently, expression profiling and pathway study using microarray analysis of dopaminergic neurons removed from the frozen brains of patients with PD has shown that there are several significantly dysregulated pathways. Among these pathways, the PI3K/Akt/mTOR signaling pathway is considered a central hub. To associate the prosurvival role of eEF1A2 with that of the PI3K/Akt/mTOR pathway, we investigated the relative expression of isoforms further for $\mathrm{PI} 3 \mathrm{~K}$, Akt, and mTOR families at the mRNA level.

In the present study, we found that all of the three Akt isoforms were relatively increased in their expression in differentiated SH-SY5Y cells after exposure to $\mathrm{MPP}^{+}$. Although the isoforms share a high degree of structural homology, several studies suggested distinct roles for each of the Akt family kinases [32-35]. It is recognized that Akt1 is involved in the prosurvival processes of the cell, including antiapoptosis. The role of Akt2 and Akt3 in the induction of caspasedependent apoptosis has been reported [36, 37]. Studies of the role of eEF1A2 on activation of Akt are mainly focused on the Aktl isoform, whose phosphorylation sites are at Thr 308 and Ser $473[22,23]$. Western blotting using the antibody 


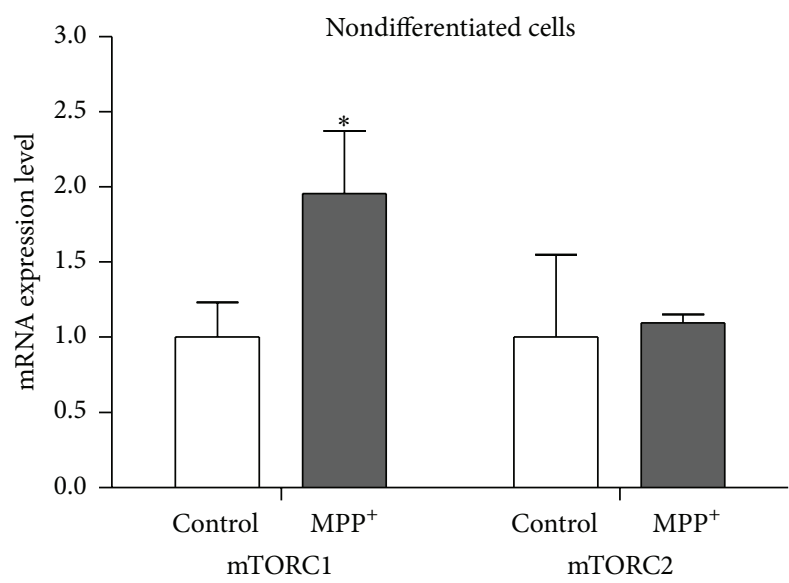

(a)

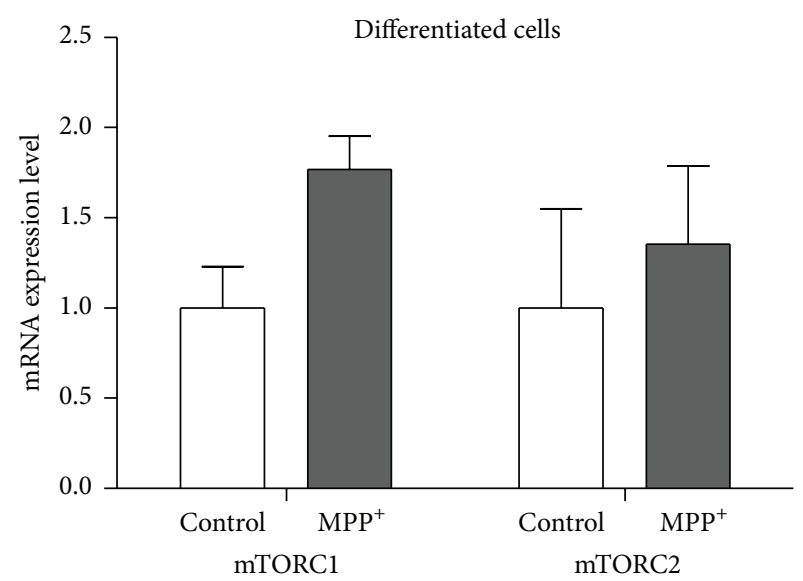

(b)

FIGURE 7: mRNA expression levels of $m$ TORC1 and $m$ TORC2 in nondifferentiated SH-SY5Y cells (a) and mRNA expression levels of $m$ TORC1 and $m$ TORC2 in differentiated SH-SY5Y cells (b). For neuronal differentiation, SH-SY5Y cells were treated with $10 \mu \mathrm{M}$ retinoic acid for three days before exposure to $\mathrm{MPP}^{+}$. The control groups for nondifferentiated and differentiated SH-SY5Y cells were treated with the same medium without $\mathrm{MPP}^{+}$. Real-time quantitative PCRs were repeated three times in triplicate measurement. Data are expressed as relative to a control and shown as mean \pm SEM. $*$ indicates $P<0.05$ versus control of each group.

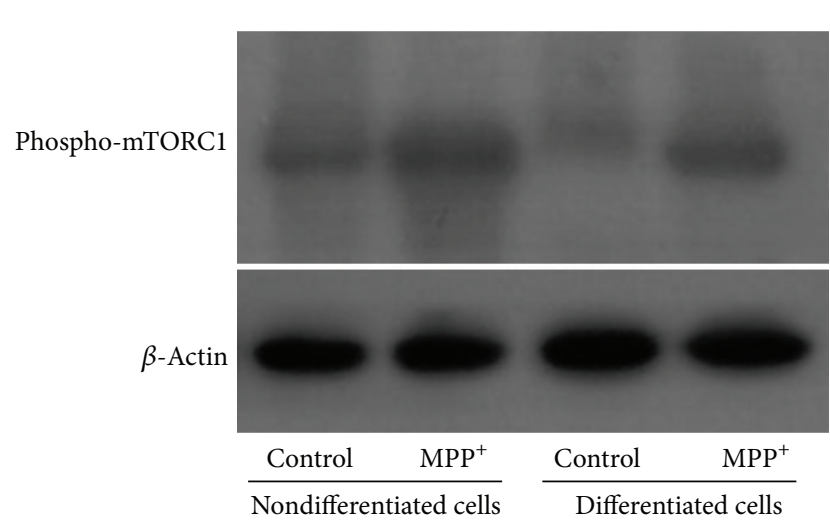

(a)

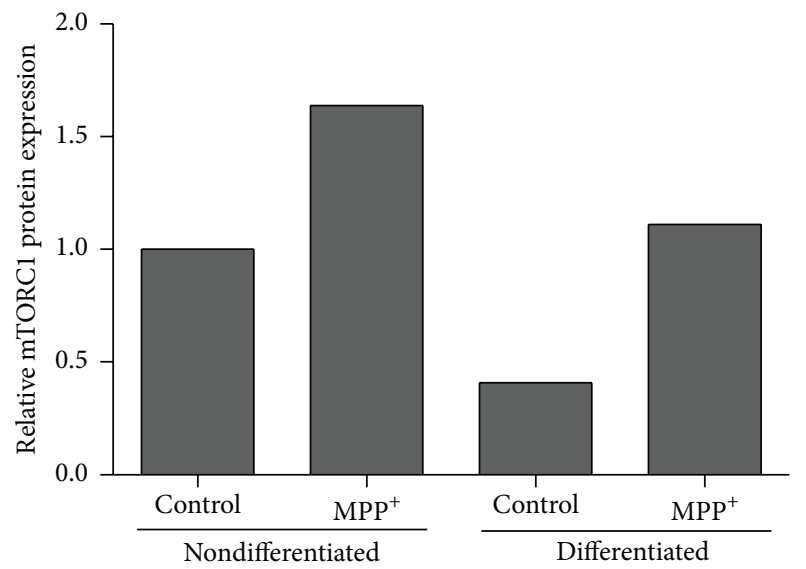

(b)

FIGURE 8: Relative protein expression of phospho-mTORC1 in nondifferentiated and differentiated SH-SY5Y cells by Western blot. For neuronal differentiation, SH-SY5Y cells were treated with $10 \mu \mathrm{M}$ retinoic acid for three days before exposure to MPP ${ }^{+}$. The control groups for nondifferentiated and differentiated SH-SY5Y cells were treated with the same medium without MPP ${ }^{+}$. (b) represents the quantification of the band density normalized to actin, relative to a nondifferentiated control.

against phospho-Akt (Ser 473) in our study also showed an increased expression of phospho-Akt protein in $\mathrm{MPP}^{+}$treated SH-SY5Y cells, those being both nondifferentiated and differentiated, similar to previous studies $[4,38]$. It should be noted that antibody against the Ser- 473 residue of Akt1 might bind to equivalent residues of Akt 2 and Akt3. There is evidence of differential regulation of the isoforms after induction using a common Akt activator [39]. Whether eEF1A2 is a common Akt activator and possibly contributes to isoform specific regulation of Akt in PD and other cellular processes remains unknown at this time.

We investigated the downstream signaling of Akt further. Activation of the PI3K/Akt/pathway promotes survival and neuronal protection by mTOR activation [40]. mTOR, the mammalian target of rapamycin, exists in two distinct complexes, mTORC1 and mTORC2 [41]. The PI3K/Akt pathway is a major upstream modulator of mTORC1 [42]. mTORC1 is the key player in the modulation of the autophagic process, with mTORC2 implicated in Akt activation [40]. Studies on neuroblastoma cellular models of PD showed the reduced phosphorylation of the major autophagy repressor mTORC1 after exposure to either 2-12 hours of $1000 \mu \mathrm{M} \mathrm{MPP}^{+}$for differentiated cells or $8-16$ hours of $50 \mu \mathrm{M}$ 6-OHDA for nondifferentiated cells $[43,44]$. Less is known about the role of mTORC2 in PD. Our Western blotting using the antibody against phospho-mTORC1 also showed an increased expression of the phospho-mTORC1 protein in SH-SY5Y cells, after 24-hour exposure to $500 \mu \mathrm{M} \mathrm{MPP}^{+}$ 


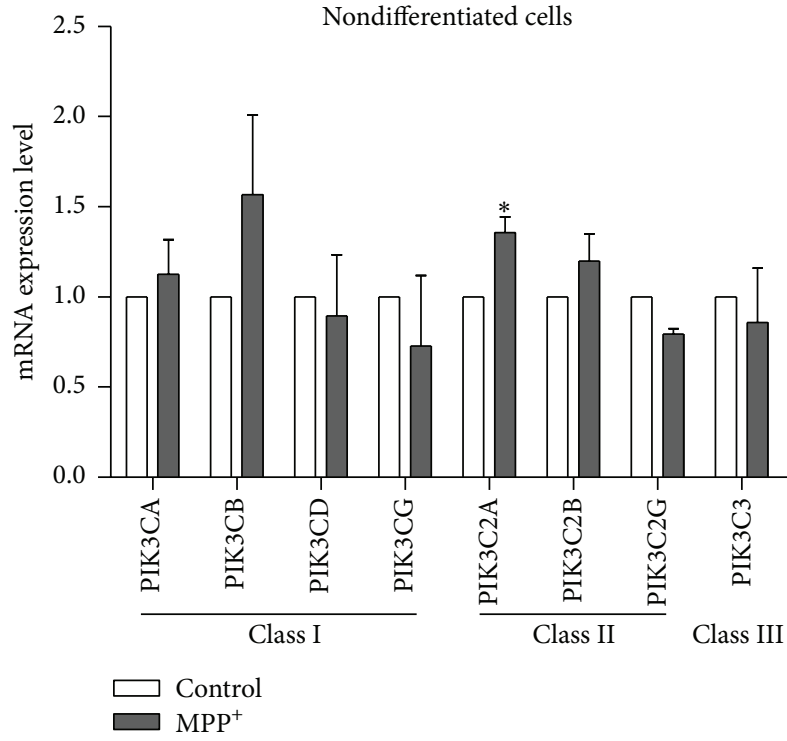

(a)

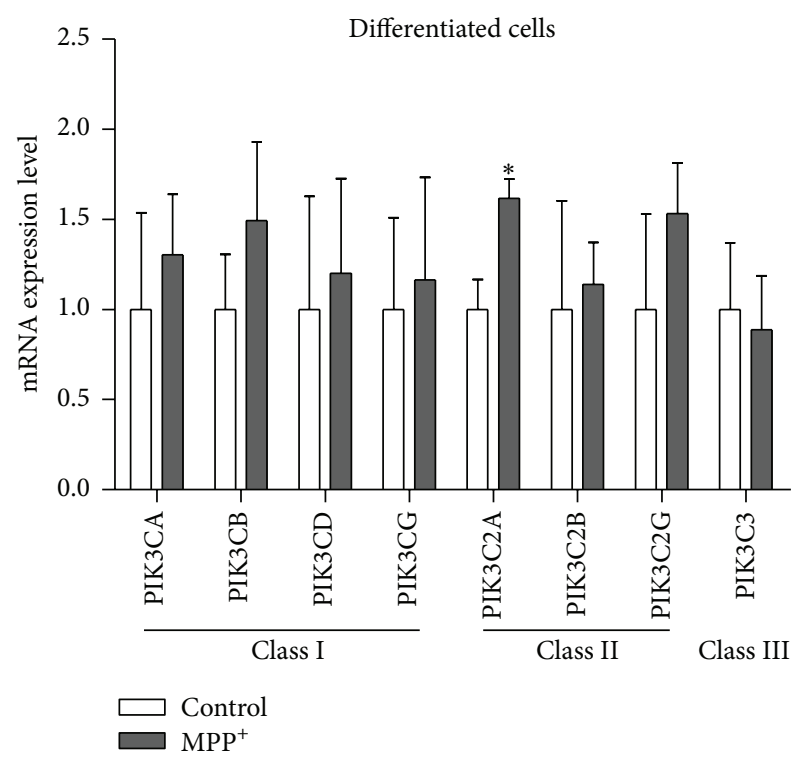

(b)

FIGURE 9: mRNA expression levels of genes of PI3K classes I, II, and III in nondifferentiated SH-SY5Y cells (a) and mRNA expression levels of genes of PI3K classes I, II, and III in differentiated SH-SY5Y cells (b). For neuronal differentiation, SH-SY5Y cells were treated with $10 \mu \mathrm{M}$ retinoic acid for three days before exposure to $\mathrm{MPP}^{+}$. The control groups for nondifferentiated and differentiated SH-SY5Y cells were treated with the same medium without $\mathrm{MPP}^{+}$. Real-time quantitative PCRs were repeated three times in triplicate measurement. Data are expressed as relative to a control and shown as mean \pm SEM. $*$ indicates $P<0.05$ versus control of each group.

and $1000 \mu \mathrm{M} \mathrm{MPP}{ }^{+}$for nondifferentiated and differentiated cells, respectively. The protein results were consistent with the mRNA results. Discrepancies between our and previous studies remain to be investigated. There has not been any study of the relationship between eEF1A isoforms and mTOR activation in PD. Evidence from acute brain slices has shown that the induction of protein synthesis-dependent hippocampal long-term potentiation that increases the local expression of eEF1A1 is mediated by the mTORCl signaling [45]. A study of pheochromocytoma cells also showed that stimulation with a nerve growth factor causes preferential synthesis of eEF1A1 over eEF1A2. This process is mediated by mTORC1 [46]. Our results provide additional information, at the mRNA level, regarding the correlation between the expression of isoforms of eEF1A and mTOR in PD.

Next, we investigated the PI3Ks, the upstream regulator for Akt activation. There are three classes (I-III) of PI3Ks in mammals. Involvement of PI3Ks in various cellular models of PD is usually investigated using a PI3K inhibitor, LY294002, which inhibits most of members of the PI3K classes [46]. Data is lacking with regard to the predominant class of PI3Ks involved in neuroprotection. Our present data showed, at the mRNA level, that almost all members of PI3Ks, except class III, were likely to be upregulated when SH-SY5Y cells were exposed to $\mathrm{MPP}^{+}$.

Parkinson's disease is a complex disorder. Data from microarray-based gene expression profiling on human substantia nigra dopaminergic neurons dissected using laser microdissection showed both upregulation and downregulation of genes of the PI3K/Akt/mTOR signaling pathway in the neurons of PD patients $[6,47]$. For example, PIK3C2G and PIK3R2, members of class II and I PI3Ks, respectively, are upregulated in human dopaminergic neurons [47]. We observed considerable variability of mRNA expression levels across the sample populations. The results derived from within each sample, represented as mean $\pm \mathrm{SD}$, were statistically significant (data not shown), while those derived from analysis across samples, represented as mean \pm SEM, were mostly insignificant. However, there was overall consistency among each gene studied. This observation was similar to the results of a previous study performed using TaqMan real-time PCR to validate the microarray data [47]. It should be also emphasized that mRNA expression levels reveal information at the level of transcriptional activation of genes but do not provide much about actual protein levels or functions. Additional work on the protein expression for each isoform of eEF1A and members of the PI3K/Akt/mTOR pathway is necessary to confirm the involvement of these genes and proteins in the mechanistic network of PD.

\section{Conclusions}

Our mRNA expression analysis is the first study grounded on the expression of gene members of the PI3K/Akt/mTOR signaling pathway in relation to those of the eEF1A isoforms in a toxin-induced cellular model of PD. Both eEF1A1 and eEF1A2 may be involved in the response to $\mathrm{MPP}^{+}$of dopaminergic cells, although eEF1A2 seems to be predominant. Association between eEF1A2 and PI3K/Akt/mTOR has been supported in other cell types $[22,48]$. Whether or not eEF1A2 could be a potential candidate for pharmacological intervention remains to be seen. Further studies to address the relationship 
or interaction between eEF1A isoforms and PI3K/Akt/mTOR members, including other cell survival pathways, should be conducted in available cellular or animal models of PD. In addition, overexpression study for eEF1A may accentuate the effects of the PI3K/Akt/mTOR pathway. The current results could be a useful adjunct to support previous studies using the microarray-based gene profiling analysis, although validation of the gene expression in human dopaminergic neurons of $\mathrm{PD}$ patients remains to be performed. Lastly, our study on the PI3K/Akt/mTOR genes in SH-SY5Y dopaminergic cells also provides a reference gene framework for researchers working in PD. The expression pattern will offer useful clues about the function of the PI3K/Akt/mTOR pathway during $\mathrm{PD}$ pathogenesis and regulation of neuroprotection.

\section{Conflict of Interests}

The authors declare that there is no conflict of interests regarding the publication of this paper.

\section{Acknowledgments}

This research is under the research framework of Mahidol University. This research was supported by grants from Thailand Research Fund and Mahidol University (IRG5780011 to P. Dharmasaroja) and Thailand Research Fund Royal Golden Jubilee Ph.D. Scholarship (PHD/0058/2556 to K. Khwanraj).

\section{References}

[1] J. A. Engelman, J. Luo, and L. C. Cantley, "The evolution of phosphatidylinositol 3-kinases as regulators of growth and metabolism," Nature Reviews Genetics, vol. 7, no. 8, pp. 606-619, 2006.

[2] P. T. Hawkins, K. E. Anderson, K. Davidson, and L. R. Stephens, "Signalling through Class I PI3Ks in mammalian cells," Biochemical Society Transactions, vol. 34, no. 5, pp. 647-662, 2006.

[3] A. Chen, L.-J. Xiong, Y. Tong, and M. Mao, "Neuroprotective effect of brain-derived neurotrophic factor mediated by autophagy through the PI3K/Akt/mTOR pathway," Molecular Medicine Reports, vol. 8, no. 4, pp. 1011-1016, 2013.

[4] K. Nakaso, S. Ito, and K. Nakashima, "Caffeine activates the PI3K/Akt pathway and prevents apoptotic cell death in a Parkinson's disease model of SH-SY5Y cells," Neuroscience Letters, vol. 432, no. 2, pp. 146-150, 2008.

[5] S. M. S. Yakhine-Diop, J. M. Bravo-San Pedro, R. GómezSánchez et al., "G2019S LRRK2 mutant fibroblasts from Parkinson's disease patients show increased sensitivity to neurotoxin 1methyl-4-phenylpyridinium dependent of autophagy," Toxicology, vol. 324, pp. 1-9, 2014.

[6] M. Elstner, C. M. Morris, K. Heim et al., "Expression analysis of dopaminergic neurons in Parkinson's disease and aging links transcriptional dysregulation of energy metabolism to cell death," Acta Neuropathologica, vol. 122, no. 1, pp. 75-86, 2011.

[7] H. Aleyasin, M. W. C. Rousseaux, P. C. Marcogliese et al., "DJ1 protects the nigrostriatal axis from the neurotoxin MPTP by modulation of the AKT pathway," Proceedings of the National Academy of Sciences of the United States of America, vol. 107, no. 7, pp. 3186-3191, 2010.
[8] C. Malagelada, Z. H. Jin, V. Jackson-Lewis, S. Przedborski, and L. A. Greene, "Rapamycin protects against neuron death in in vitro and in vivo models of Parkinson's disease," Journal of Neuroscience, vol. 30, no. 3, pp. 1166-1175, 2010.

[9] S. Timmons, M. F. Coakley, A. M. Moloney, and C. O’ Neill, "Akt signal transduction dysfunction in Parkinson's disease," Neuroscience Letters, vol. 467, no. 1, pp. 30-35, 2009.

[10] L. S. Tain, H. Mortiboys, R. N. Tao, E. Ziviani, O. Bandmann, and A. J. Whitworth, "Rapamycin activation of 4E-BP prevents parkinsonian dopaminergic neuron loss," Nature Neuroscience, vol. 12, no. 9, pp. 1129-1135, 2009.

[11] C. K. Tsang, H. Qi, L. F. Liu, and X. F. S. Zheng, "Targeting mammalian target of rapamycin (mTOR) for health and diseases," Drug Discovery Today, vol. 12, no. 3-4, pp. 112-124, 2007.

[12] S. M. Knudsen, J. Frydenberg, B. F. C. Clark, and H. Leffers, "Tissue-dependent variation in the expression of elongation factor-1 alpha isoforms: isolation and characterisation of a cDNA encoding a novel variant of human elongation-factor 1 alpha," European Journal of Biochemistry, vol. 215, no. 3, pp. 549554, 1993.

[13] S. Kahns, A. Lund, P. Kristensen et al., “The elongation factor 1 A-2 isoform from rabbit: cloning of the cDNA and characterization of the protein," Nucleic Acids Research, vol. 26, no. 8, pp. 1884-1890, 1998.

[14] D. M. Chambers, J. Peters, and C. M. Abbott, "The lethal mutation of the mouse wasted (wst) is a deletion that abolishes expression of a tissue-specific isoform of translation elongation factor $1 \alpha$, encoded by the Eefla2 gene," Proceedings of the National Academy of Sciences of the United States of America, vol. 95, no. 8, pp. 4463-4468, 1998.

[15] J. Condeelis, "Elongation factor $1 \alpha$, translation and the cytoskeleton," Trends in Biochemical Sciences, vol. 20, no. 5, pp. 169-170, 1995.

[16] D. B. McClatchy, C. R. Knudsen, B. F. Clark, R. A. Kahn, R. A. Hall, and A. I. Levey, "Novel interaction between the $\mathrm{M}_{4}$ muscarinic acetylcholine receptor and elongation factor 1A2," The Journal of Biological Chemistry, vol. 277, no. 32, pp. 2926829274, 2002.

[17] N. Anand, S. Murthy, G. Amann et al., "Gene encoding protein elongation factor EEF1A2 is a putative oncogene in ovarian cancer," Nature Genetics, vol. 31, no. 3, pp. 301-305, 2002.

[18] V. A. L. Tomlinson, H. J. Newbery, N. R. Wray et al., "Translation elongation factor eEF1A2 is a potential oncoprotein that is overexpressed in two-thirds of breast tumours," BMC Cancer, vol. 5, article 113, 2005.

[19] M.-H. Lee and Y.-J. Surh, "eEF1A2 as a putative oncogene," Annals of the New York Academy of Sciences, vol. 1171, pp. 8793, 2009.

[20] R. Li, H. Wang, B. N. Bekele et al., "Identification of putative oncogenes in lung adenocarcinoma by a comprehensive functional genomic approach," Oncogene, vol. 25 , no. 18 , pp. $2628-$ 2635, 2006.

[21] M. J. Devine, H. Plun-Favreau, and N. W. Wood, "Parkinson's disease and cancer: two wars, one front," Nature Reviews Cancer, vol. 11, no. 11, pp. 812-823, 2011.

[22] A. Amiri, F. Noei, S. Jeganathan, G. Kulkarni, D. E. Pinke, and J. M. Lee, "eEF1A2 activates Akt and stimulates Akt-dependent actin remodeling, invasion and migration," Oncogene, vol. 26, no. 21, pp. 3027-3040, 2007.

[23] Z. Li, C.-F. Qi, D.-M. Shin et al., "Eefla2 promotes cell growth, inhibits apoptosis and activates JAK/STAT and AKT signaling 
in mouse plasmacytomas," PLoS ONE, vol. 5, no. 5, Article ID e10755, 2010.

[24] E. Chen, G. Proestou, D. Bourbeau, and E. Wang, "Rapid upregulation of peptide elongation factor EF- $1 \alpha$ protein levels is an immediate early event during oxidative stress-induced apoptosis," Experimental Cell Research, vol. 259, no. 1, pp. 140$148,2000$.

[25] R. Chang and E. Wang, "Mouse translation elongation factor eEF1A-2 interacts with Prdx-I to protect cells against apoptotic death induced by oxidative stress," Journal of Cellular Biochemistry, vol. 100, no. 2, pp. 267-278, 2007.

[26] H. Yamaguchi, S. Yoshida, E. Muroi et al., "Phosphoinositide 3-kinase signaling pathway mediated by p110 $\alpha$ regulates invadopodia formation," Journal of Cell Biology, vol. 193, no. 7, pp. 1275-1288, 2011.

[27] D. Pachow, N. Andrae, N. Kliese et al., "mTORC1 inhibitors suppress meningioma growth in mouse models," Clinical Cancer Research, vol. 19, no. 5, pp. 1180-1189, 2013.

[28] S. Tripathy and D. B. Jump, "Elovl5 regulates the mTORC2Akt-FOXO1 pathway by controlling hepatic cis-vaccenic acid synthesis in diet-induced obese mice," Journal of Lipid Research, vol. 54, no. 1, pp. 71-84, 2013.

[29] F. M. Lopes, R. Schröder, M. L. C. da Frota Jr. et al., "Comparison between proliferative and neuron-like SH-SY5Y cells as an in vitro model for Parkinson disease studies," Brain Research, vol. 1337, pp. 85-94, 2010.

[30] Y.-T. Cheung, W. K.-W. Lau, M.-S. Yu et al., "Effects of all-transretinoic acid on human SH-SY5Y neuroblastoma as in vitro model in neurotoxicity research," NeuroToxicology, vol. 30, no. 1, pp. 127-135, 2009.

[31] L.-B. Ruest, R. Marcotte, and E. Wang, "Peptide elongation factor eEF1A-2/S1 expression in cultured differentiated myotubes and its protective effect against caspase-3-mediated apoptosis," The Journal of Biological Chemistry, vol. 277, no. 7, pp. 54185425, 2002.

[32] W. S. Chen, P.-Z. Xu, K. Gottlob et al., "Growth retardation and increased apoptosis in mice with homozygous disruption of the akt1 gene," Genes \& Development, vol. 15, no. 17, pp. 2203-2208, 2001.

[33] H. Cho, J. Mu, J. K. Kim et al., "Insulin resistance and a diabetes mellitus-like syndrome in mice lacking the protein kinase Akt2 (PKB $\beta$ )," Science, vol. 292, no. 5522, pp. 1728-1731, 2001.

[34] T. F. Franke, "PI3K/Akt: getting it right matters," Oncogene, vol. 27, no. 50, pp. 6473-6488, 2008.

[35] J. Laine, G. Künstle, T. Obata, and M. Noguchi, "Differential regulation of Akt kinase isoforms by the members of the TCL1 oncogene family," Journal of Biological Chemistry, vol. 277, no. 5, pp. 3743-3751, 2002.

[36] Q. Huang, F. Lan, Z. Zheng et al., "Akt2 kinase suppresses glyceraldehyde-3-phosphate dehydrogenase (GAPDH)mediated apoptosis in ovarian cancer cells via phosphorylating gapdh at threonine 237 and decreasing its nuclear translocation," The Journal of Biological Chemistry, vol. 286, no. 49, pp. 42211-42220, 2011.

[37] Y. Shao and A. E. Aplin, "Akt3-mediated resistance to apoptosis in B-RAF-targeted melanoma cells," Cancer Research, vol. 70, no. 16, pp. 6670-6681, 2010.

[38] W. Cui, W. Li, R. Han et al., "PI3-K/Akt and ERK pathways activated by VEGF play opposite roles in $\mathrm{MPP}^{+}$-induced neuronal apoptosis," Neurochemistry International, vol. 59, no. 6, pp. 945953, 2011.
[39] J.-I. Okano, I. Gaslightwala, M. J. Birnbaum, A. K. Rustgi, and H. Nakagawa, "Akt/protein kinase B isoforms are differentially regulated by epidermal growth factor stimulation," The Journal of Biological Chemistry, vol. 275, no. 40, pp. 30934-30942, 2000.

[40] D. Heras-Sandoval, J. M. Pérez-Rojas, J. Hernández-Damián, and J. Pedraza-Chaverri, "The role of PI3K/AKT/mTOR pathway in the modulation of autophagy and the clearance of protein aggregates in neurodegeneration," Cellular Signalling, vol. 26, no. 12, pp. 2694-2701, 2014.

[41] P. T. Bhaskar and N. Hay, "The two TORCs and Akt," Developmental Cell, vol. 12, no. 4, pp. 487-502, 2007.

[42] B. D. Manning and L. C. Cantley, "AKT/PKB signaling: navigating downstream," Cell, vol. 129, no. 7, pp. 1261-1274, 2007.

[43] K. Arsikin, T. Kravic-Stevovic, M. Jovanovic et al., "Autophagydependent and -independent involvement of AMP-activated protein kinase in 6-hydroxydopamine toxicity to SH-SY5Y neuroblastoma cells," Biochimica et Biophysica Acta (BBA)Molecular Basis of Disease, vol. 1822, no. 11, pp. 1826-1836, 2012.

[44] J. Deguil, D. Jailloux, G. Page et al., "Neuroprotective effects of pituitary adenylate cyclase-activating polypeptide (PACAP) in $\mathrm{MPP}^{+}$-induced alteration of translational control in neuro-2a neuroblastoma cells," Journal of Neuroscience Research, vol. 85, no. 9, pp. 2017-2025, 2007.

[45] P. Tsokas, E. A. Grace, P. Chan et al., "Local protein synthesis mediates a rapid increase in dendritic elongation factor $1 \mathrm{~A}$ after induction of late long-term potentiation," The Journal of Neuroscience, vol. 25, no. 24, pp. 5833-5843, 2005.

[46] G. Zhu, X. Wang, S. Wu, and Q. Li, "Involvement of activation of $\mathrm{PI} 3 \mathrm{~K} /$ Akt pathway in the protective effects of puerarin against $\mathrm{MPP}^{+}$-induced human neuroblastoma SH-SY5Y cell death," Neurochemistry International, vol. 60, no. 4, pp. 400-408, 2012.

[47] F. Simunovic, M. Yi, Y. Wang et al., "Gene expression profiling of substantia nigra dopamine neurons: further insights into Parkinson's disease pathology," Brain, vol. 132, no. 7, pp. 17951809, 2009.

[48] E. Petroulakis and E. Wang, "Nerve growth factor specifically stimulates translation of eukaryotic elongation factor 1A-1 (eEF1A-1) mRNA by recruitment to polyribosomes in PC12 cells," The Journal of Biological Chemistry, vol. 277, no. 21, pp. 18718-18727, 2002. 


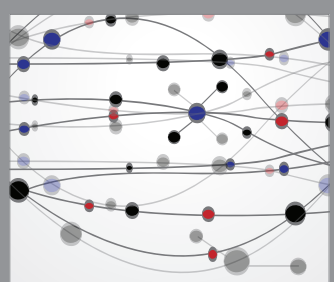

The Scientific World Journal
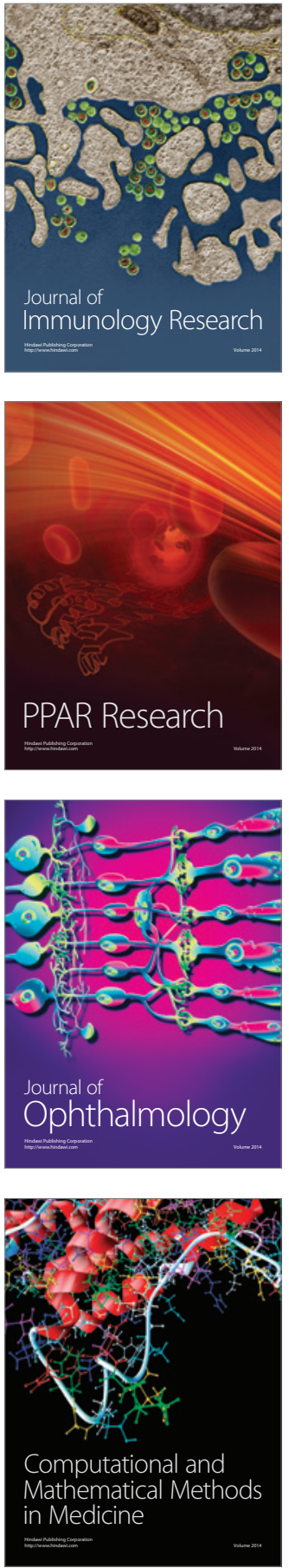

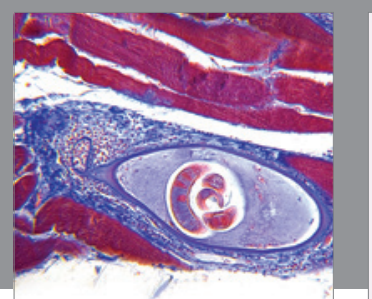

Gastroenterology Research and Practice

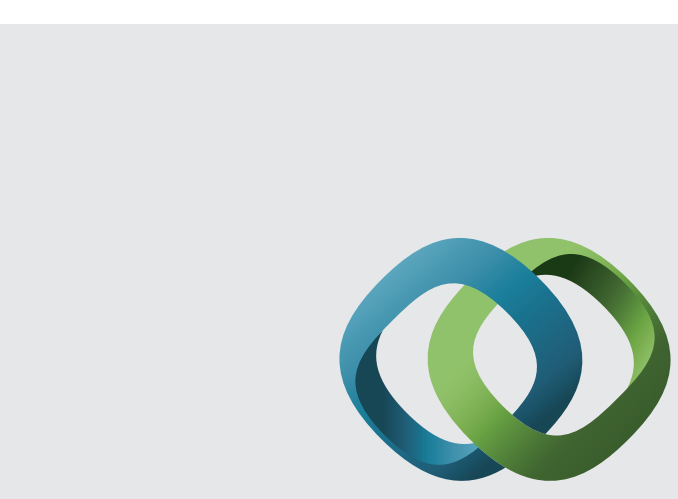

\section{Hindawi}

Submit your manuscripts at

http://www.hindawi.com
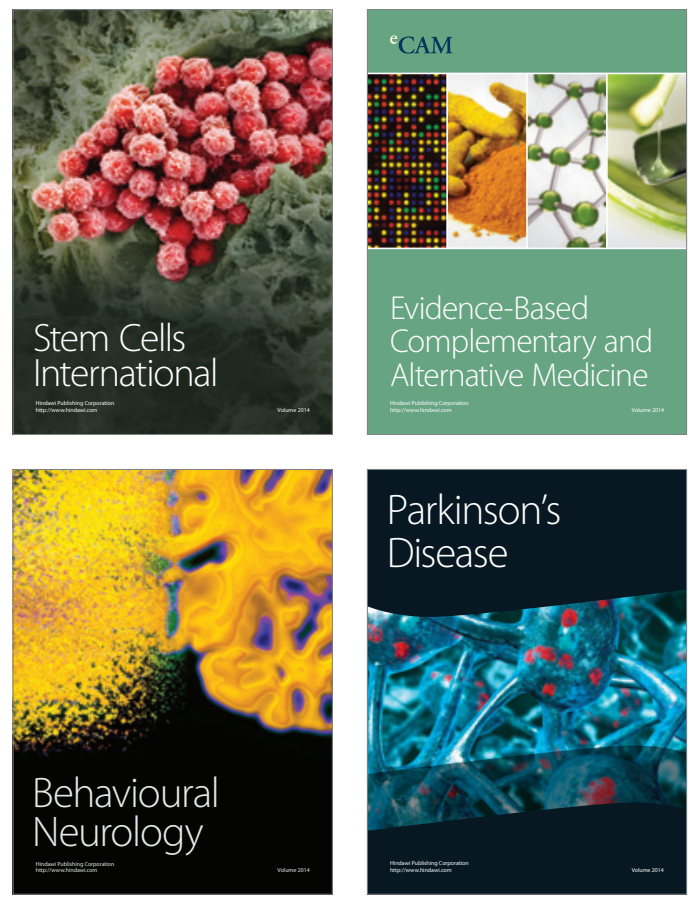
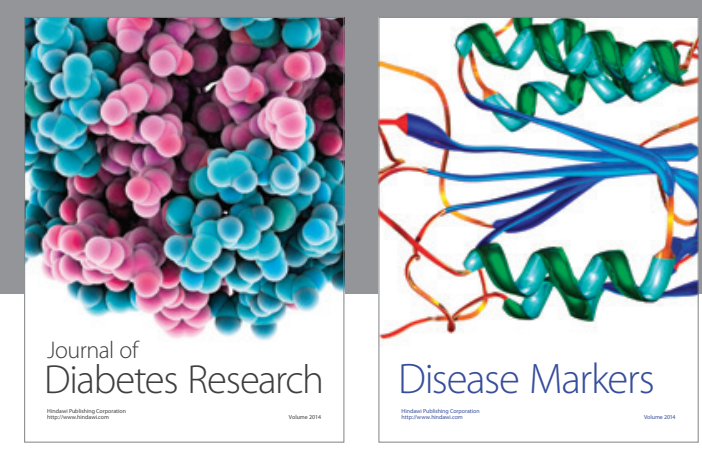

Disease Markers
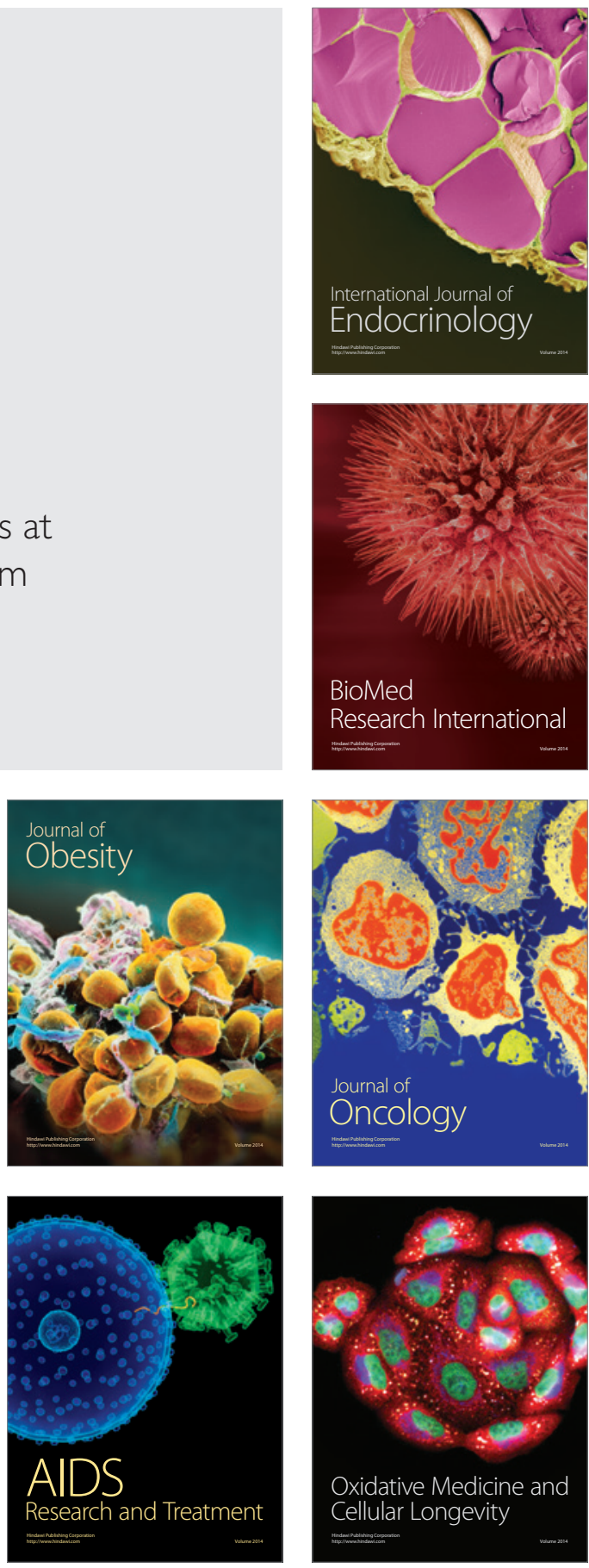